\title{
Recurrent cytomegalovirus disease, visceral leish- maniosis, and Legionella pneumonia after liver transplantation: a case report
}

\author{
[Infection récurrente à cytomégalovirus, leishmaniose viscérale et légionellose à la \\ suite d'une transplantation hépatique : une étude de cas]
}

Nermin Halkic MD, ${ }^{*}$ Riadh Ksontini MD, ${ }^{*}$ Beatrix Scholl MD, ${ }^{*}$ Catherine Blanc MD, $†$ Tibor Kovacsovics MD, $\ddagger$ Pascal Meylan MD, $\mathfrak{S}$ Carmen Muheim MD, $\mathfrak{\$}$ Michel Gillet MD, ${ }^{*}$ François Mosimann $M{ }^{*}$

\begin{abstract}
Purpose: Recurrent cytomegalovirus (CMV) disease is a frequent complication of liver transplantation. Visceral leishmaniosis in a transplant recipient is, on the other hand, extremely rare and only two cases of kala-azar have been described after liver transplantation. Immunosuppressed patients are known to be at risk of Legionella infection and the relationship between infection with this organism and hospital water supplies has been well described. These three diseases carry a high mortality rate. Our report examines the potential relationship between these complications.
\end{abstract}

Clinical features: We describe the case of a liver transplant recipient who presented the three complications successively and survived. After reviewing the literature, we explore hypotheses linking these infections and discuss treatment strategies.

Conclusions: In the patient described, infection with leishmania probably occurred months prior to the clinical presentation, a delay that matches the incubation period of kala-azar. The simultaneous onset of leishmaniosis and of a high CMV viremia may have been a coincidence. However, CMV infection has been shown to be an independent predictor of invasive fungal infection in liver transplant recipients. CMV does indeed have a suppressive effect on the humoral and cellular immune response in vitro as well as in vivo. The clinical manifestations of leishmaniosis may, therefore, have been precipitated in this patient by the additive immunosuppressive effect of antirejection drugs and CMV.

Objectif : L'infection récurrente au cytomégalovirus (CMV) est une complication fréquente de la transplantation hépatique. La leishmaniose viscérale chez un receveur d'organe est, par contre, extrêmement rare et on ne rapporte que deux cas de kala-azar à la suite d'une greffe de foie. Les patients immunodéprimés sont à risque d'infections à Légionella et la relation entre cet organisme et l'alimentation en eau des hôpitaux a été bien décrite. Ces trois maladies présentent un taux de mortalité élevée. Nous étudions ici la relation possible entre ces complications.

Éléments cliniques : Nous décrivons le cas d'un patient greffé du foie qui a présenté successivement les trois complications et a survécu. Après avoir passé en revue les publications, nous explorons des hypothèses pouvant relier ces infections et discutons des traitements possibles.

Conclusion : Chez ce patient, l'infection à Leishmania est probablement survenue plusieurs mois avant les manifestations cliniques, ce qui correspond à la période d'incubation du kala-azar. La survenue simultanée d'une leishmaniose et d'une importante virémie au CMV pourrait n'être qu'une coïncidence. Cependant, l'infection au CMV s'est révélée un prédicteur indépendant d'infection fongique invasive chez les receveurs d'un foie. Le CMV a certainement un effet inhibiteur sur la réponse immunitaire humorale et cellulaire, in vitro aussi bien qu'in vivo. Les manifestations cliniques de la leishmaniose peuvent donc avoir été précipitées par l'effet immunodépresseur supplémentaire des médicaments anti-rejet et du CMV.



ECURRENT cytomegalovirus (CMV) disease is an uncommon complication of liver transplantation. Visceral leishmaniosis is even more rare as only two cases have been described. Immunosuppressed patients are also at risk of Legionella infection as this micro-organism may contaminate hospital water supplies. We

From the Departments of Surgery, ${ }^{*}$ Anesthesiology, $†$ the Division of Hematology, $\ddagger$ and the Institute of Microbiology, $\$$ Lausanne University Hospital (CHUV), Lausanne, Switzerland. Address correspondence to: Dr. Nermin Halkic, Service de Chirurgie, 1011 Lausanne-CHUV, Switzerland. Phone: 41-21-3142248;

Fax: 41-21-3142360; E-mail: nhalkic@hospvd.ch Accepted for publication February 27, 2003.

Revision accepted September 8, 2003. 
report on a liver transplant recipient who presented successively all these three potentially lethal complications and survived.

\section{Case report}

The medical history of the 59-yr-old Caucasian male patient included three myocardial infarcts and coronary bypass surgery. One year before admission, he presented with fatigue, coagulopathy and refractory ascites. The diagnosis of auto-immune cirrhosis was reached, including autoimmune hepatitis and primary biliary cirrhosis, by the detection of high titers of anti-smooth muscle antibodies and a liver biopsy. Steroids were prescribed for six months. This did not prevent deterioration of the liver function so that the patient had eventually to be listed for liver transplantation. The operation and the early postoperative course were uneventful. The patient was discharged home after three weeks on tacrolimus $(2 \times 3$ $\left.\mathrm{mg} \cdot \mathrm{day}^{-1}\right)$ and prednisone $\left(20 \mathrm{mg} \cdot \mathrm{day}^{-1}\right)$ immunosuppression. Although the donor's CMV serology was positive and the recipient's negative, no antiviral prophylaxis was administered.

On postoperative day 41 (Figure 1), the patient presented with fever, chills and alteration of the liver function tests. CMV detection on buffy coat leucocytes was positive by shell vial assay, amounting to 540 infectious units (IU) per $10^{6}$ peripheral blood lymphocytes (PBL). Intravenous ganciclovir $\left(5 \mathrm{mg} \cdot \mathrm{kg}^{-1}\right.$ every $12 \mathrm{hr}$ ) was prescribed for 14 days. The symptoms subsided and the patient could be discharged with a negative buffy coat test. Only four days later, he was re-admitted with the same clinical picture and a positive buffy coat test $\left(54 \mathrm{IU} / 10^{6} \mathrm{PBL}\right)$. Intravenous ganciclovir was restarted for another two weeks. This was apparently successful but on postoperative day 93, the CMV disease relapsed (33 $\left.\mathrm{IU} / 10^{6} \mathrm{PBL}\right)$. Ganciclovir was again administered for two weeks.

On postoperative day 130 , the patient was readmitted with fever, diarrhea and extreme fatigue. The buffy coat test was positive ( $\left.350 \mathrm{IU} / 10^{6} \mathrm{PBL}\right)$. This time, the symptoms failed to improve under ganciclovir treatment: fever spikes and chills occurred every evening. Pancytopenia developed: a bone marrow biopsy demonstrated leishmania parasites within monocytes and neutrophils (Figure 2). Culture and serology confirmed the diagnosis of visceral leishmaniosis (L. infantum). The patient was treated with iv antimonate salts (stibogluconate antimonate, 20 $\mathrm{mg} \cdot \mathrm{kg}^{-1}$ every day) for 28 days. Due to the pancytopenia, ganciclovir was discontinued; iv foscarnet was given instead ( $4.2 \mathrm{~g}$ every eight hours). The fever and symptoms regressed gradually; the white blood cells and platelet counts rose back to normal. However,

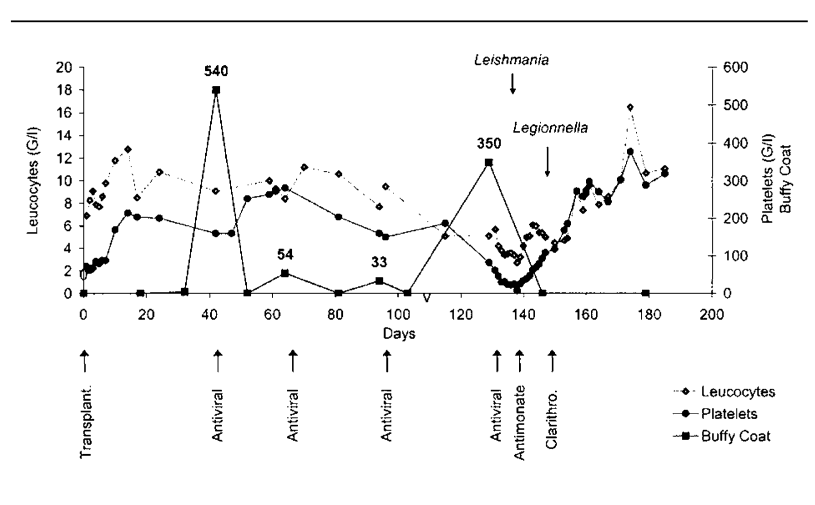

FIGURE 1 Laboratory parameters, viral DNA load and treatments.

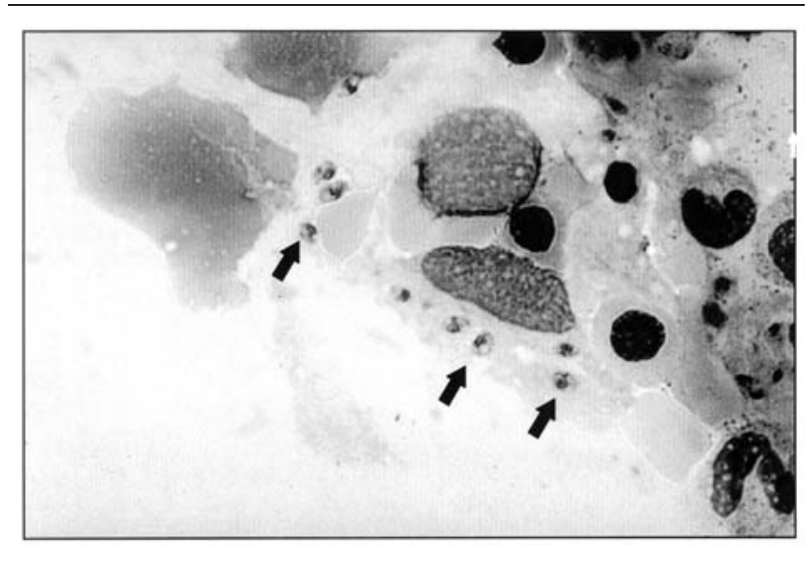

FIGURE 2 Bone marrow smear showing intracellular leishmania parasites.

three days after completion of the antimonate treatment, the fever spikes recurred and the patient complained of dyspnea. A chest $x$-ray showed a patchy, nodular infiltrate and Legionella rods were demonstrated on the bronchio-alveolar lavage fluid by immunofluorescence and culture. Intravenous clarithromycin (500 $\mathrm{mg}$ every $12 \mathrm{hr}$ for 21 days) was started and the radiological infiltrate disappeared within five days. For the next six months, the patient received oral ganciclovir prophylaxis (1 g every eight hours). Two years later, he remains free of infections.

\section{Discussion}

Infections are very common after liver transplantation, occurring in up to $70 \%$ of patients. ${ }^{1}$ Although the 
majority are bacterial, CMV infection or disease represent the most frequent identified organism. ${ }^{2}$ Recurrent CMV disease after therapy is however unusual. It can be anticipated when a positive organ is allocated to a seronegative recipient $(\mathrm{D}+/ \mathrm{R}-)$ or after anti-rejection therapy. ${ }^{3}$ In these settings, mortality is significantly higher than in a case of primary disease $(55 \%$ vs $13 \%){ }^{4}$ which may explain the scarcity of reports describing three or more recurrences. This patient suffered three relapses in a $\mathrm{D}+/ \mathrm{R}$ - constellation and was treated three times by $i v$ ganciclovir and once by foscarnet. In retrospect, primary prophylaxis may have been more efficacious than pre-emptive therapy but it was assumed at the time that mild or moderate CMV disease could induce and promote subsequent long-term protection anti-CMV antibodies. ${ }^{5}$ Similarly, secondary prophylaxis after the initial episode may have eased the clinical course. This view is supported by a retrospective analysis of the leukocyte CMV DNA load by real time polymerase chain reaction testing that showed a minimal decrease only during the first ganciclovir treatment. Subsequent courses resulted in a 1.5 to $2 \log$ decrease of CMV DNA load but, at the end of every ganciclovir treatment, substantial amounts of CMV DNA were still detectable, thus suggesting a persistent infection (data not shown). The efficacy of the secondary oral ganciclovir prophylaxis given after the third relapse strengthens further the hypothesis that prophylaxis would have been beneficial after the primary infection already. In addition, CMV having an immunosuppressive effect of its own, ${ }^{6,7}$ chemoprophylaxis might also have impacted positively on the course of the leishmaniosis and of the Legionella pneumonia.

Visceral leishmaniosis after organ transplantation has been described on some 26 occasions, mostly in renal patients ${ }^{8,9}$ and, to the best of our knowledge, ours is only the third case following liver grafting. ${ }^{10,11}$ The mortality is high, as Berenguer et al. reported five deaths out of 18 patients. ${ }^{6}$ In the patient described, as the signs and symptoms were non-specific, and since serologic testing of the donor's blood was negative, the diagnosis was reached by bone marrow biopsy only. The simultaneous occurrence of leishmaniosis and of a high CMV viremia may have been a coincidence but a retrospective interview of the patient revealed a trip to Turkey the year before the transplantation. It is therefore possible that the clinical presentation of the parasitic infection was triggered by the CMV disease. A similar mechanism has been described by George et al. who showed that CMV infection is an independent predictor of invasive fungal infection in liver transplant recipients. ${ }^{9}$ The same phenomenon might explain the Legionella pneumonia of our patient, by the additive effects of CMV and of the tacrolimus-based immunosuppression regimen. ${ }^{12}$ Singh et al. have indeed suggested that tacrolimus induces more fungal and Legionella pulmonary infections in liver transplant recipients than cyclosporine does. ${ }^{13,14}$

In conclusion, this case report suggests that primary CMV prophylaxis may be indicated in the $\mathrm{D}+/ \mathrm{R}$ constellation. It indicates also that persistent or recurrent CMV disease in spite of treatment requires an aggressive search for other and possibly rare infectious agents.

\section{References}

1 Kibbler CC. Infections in liver transplantation: risk factors and strategies for prevention. J Hosp Infect 1995; 30(Suppl): 209-17.

2 Kanj SS, Sharara AI, Clavien PA, Hamilton JD. Cytomegalovirus infection following liver transplantation: review of the literature. Clin Infect Dis 1996; 22: 537-49.

3 Falagas ME, Snydman DR. Recurrent cytomegalovirus disease in solid-organ transplant recipients. Transplant Proc 1995; 27(Suppl 1): 34-7.

4 Falagas ME, Snydman DR, Griffith J, Werner BG, Freeman R, Rohrer R. Clinical and epidemiological predictors of recurrent cytomegalovirus disease in orthotopic liver transplant recipients. Boston Center for Liver Transplantation CMVIG Study Group. Clin Infect Dis 1997; 25: 314-7.

5 Gane E, Saliba F, Valdecasas GJ, et al. Randomised trial of efficacy and safety of oral ganciclovir in the prevention of cytomegalovirus disease in liver-transplant recipients. The Oral Ganciclovir International Transplantation Study Group. Lancet 1997; 350: 1729-33.

6 Berenguer J, Gomez-Campdera F, Padilla B, et al. Visceral leishmaniasis (kala-azar) in transplant recipients: case report and review. Transplantation 1998; 65: 1401-4.

7 Hernandez-Perez J, Yebra-Bango M, Jimenez-Martinez $E$, et al. Visceral leishmaniasis (kala-azar) in solid organ transplantation: report of five cases and review. Clin Infect Dis 1999; 29: 918-21.

8 Horber FF, Lerut JP, Reichen J, Zimmermann A, Jaeger $P$, Malinverni R. Visceral leishmaniasis after orthotopic liver transplantation: impact of persistent splenomegaly. Transpl Int 1993; 6: 55-7.

9 George MJ, Snydman DR, Werner BG, et al. The independent role of cytomegalovirus as a risk factor for invasive fungal disease in orthotopic liver transplant recipients. Boston Center for Liver Transplantation 
CMVIG-Study Group. Cytogam, MedImmune, Inc.

Gaithersburg, Maryland. Am J Med 1997; 103:

106-13.

10 Rinaldo CR Jr, DeBiasio RL. Alteration of immunoregulatory mechanisms during cytomegalovirus mononucleosis: effect of in vitro culture on lymphocyte blastogenesis to viral antigens. Clin Immunol Immunopathol 1983; 28: 46-55.

11 Price P. Depression of humoral responses by murine cytomegalovirus infection. Immunol Cell Biol 1990; 68: 33-43.

12 Mermel LA, Maki DG. Bacterial pneumonia in solid organ transplantation. Semin Respir Infect 1990; 5: 10-29.

13 Singh N, Gayowski T, Wagener MM, Marino IR. Predictors and outcome of early- versus late-onset major bacterial infections in liver transplant recipients receiving tacrolimus (FK506) as primary immunosuppression. Eur J Clin Microbiol Infect Dis 1997; 16: 821-6.

14 Patterson WJ, Hay J, Seal DV, McLuckie JC.

Colonization of transplant unit water supplies with Legionella and protozoa: precautions required to reduce the risk of legionellosis. J Hosp Infect 1997; 37: 7-17. 